\title{
Effect Of Technological Parameters Of Production Of Tfp Preforms Of Gas Turbine Engine Blades On Their Physical And Mechanical Properties
}

\author{
${ }^{1}$ Orlov Maksim Andreyevich, ${ }^{2}$ Kalinnikov Alexander Nikolayevich, ${ }^{3}$ Polikarpova Irina \\ Aleksandrovna*, ${ }^{4}$ Bogachev Vyacheslav Vladimirovich, ${ }^{5}$ Kireinov Aleksey Valerievich, \\ ${ }^{6}$ Solodilov Vitaly Igorevich \\ ${ }^{125} \mathrm{Head}$ of Laboratory, Bauman Moscow State Technical University, Moscow, Russia \\ ${ }^{3}$ Engineer, Bauman Moscow State Technical University, Moscow, Russia, PhD student,Semenov Institute of \\ Chemical Physics, RAS, Moscow, Russia \\ ${ }^{4}$ Leading engineer, Bauman Moscow State Technical University, Moscow, Russia \\ ${ }^{6} \mathrm{PhD}$, Head of Laboratory, Semenov Institute of Chemical Physics, RAS, Moscow, Russia \\ maksim.orlov@emtc.ru ${ }^{1}, \quad \underline{\text { alexandr.kalinnikov@emtc.ru }}{ }^{2}, \quad$ ipolikarpova@emtc.ru ${ }^{3}, \quad$ vbogachev@emtc.ru ${ }^{4}$,
} aleksey.kireynov@emtc.rư ${ }^{5}, \underline{\text { vital-yo@yandex.ru }}^{6}$

Article History: Received: 11 January 2021; Accepted: 27 February 2021; Published online: 5 April 2021

\begin{abstract}
The article discusses the features of the destruction of carbon fiber reinforced plastics on the basis of tfp-preforms produced using various stitching mode parameters, and provides for studies of their physical and mechanical properties and structure. The effect of the carbon fiber laying density and the piercing step of the aramid yarn on the elastic-strength properties of composites is shown. The optimal technological parameters for creating tfp-preforms of gas turbine engine
\end{abstract} blades were chosen.

Keywords: tailored fiber placement, three-dimensional reinforced preforms, polymer composite materials, automated fiber placement, technological parameters, physical and mechanical properties.

\section{Introduction}

Carbon fiber reinforced plastics (CFRP), the preforms of which are obtained by the tailored fiber placement (TFP) technology [1,2], represent a promising class of materials with a complex of unique properties[3, 4]. Despite the fact that the TFP technology for the production of composites is largely unknown in Russia, the world experience of its application [5-7] allows to call it the most promising technology among other methods for creating 3D preforms.Preform stitching is carried out on industrial numerically controlled sewing machines. The machine automatically moves the carrier material in accordance with a software template specifically developed for produced TFP preforms. However, in the manufacture of such materials, due to the penetration of the needle of the sewing machine, defects are formed in the reinforcing structure, which can significantly reduce the elastic-strength characteristics of reinforced plastics. Since defects in patch composites can become critical and lead to premature destruction of the material, studies of the physical, mechanical and technological properties of patch reinforced plastics and their destruction mechanisms are very relevant.

When creating preforms by automated laying of the carbon fibers on a water-soluble substrate, the physical and mechanical properties of finished products are affected not only by the reinforcement scheme and the properties of the materials used (carbon and aramid fibers, substrates). To achieve optimal elastic-strength properties, the technological preform stitching parameters (roving laying density pand the piercing step $\Delta$ ) that are currently poorly studied should be also taken into account. This is particularly important for high strength parts, for example, for gas turbine engine blades (GTE blades).

It is necessary to select the optimal parameters of TFPprocess so that the maximum transverse characteristics are achieved without significantly reducing the strength along the direction of reinforcement, which is an important factor for GTE blades.

The objective of this study, which is continuation of the authors' research in [8], is to determine how the roving laying density and the piercing step of carbon fiber stitching affect the transversal properties of model flat samples and GTE blades samples, as well as to consider the structure and features of fracture of reinforced plastics on the basis of the tfp-preforms.

\section{Materials and methods}

Stitched carbon fiber reinforced plasticswere made on the basis of HTS45 12K carbon fiber (TohoTenax ${ }^{\circledR}$, Japan). The piercing thread was an aramid thread Rusar-S (LLC "Thermotex", Khotkovo, Moscow region, Russia). Preform stitching was carried out on the JCW 0100-500 automatic numerically controlled sewing machine (ZSK Stickmaschinen GmbH, Germany). All manufactured preforms were reinforced in the directions $\left[0^{\circ} ; 90^{\circ}\right]$, the laying density $\rho$ varied from 47 to $70 \mathrm{CU}$, the piercingstep $\Delta$-from 4 to $10 \mathrm{~mm}$. Control samples of carbon fiber were obtained by winding carbon fiber HTS $4512 \mathrm{~K}$ (TohoTenax ${ }^{\circledR}$, Japan) on a plate in the direction $\left[0^{\circ} ; 90^{\circ}\right]$ and pressed. 
The binder was Araldite LY 556 epoxy resin (Huntsman, Switzerland) (100 m. h.). The hardener was iso-methyltetrahydrophthalic anhydride $(90 \mathrm{~m}$. h.) (Triune Chemicals Materials (TCM), China) and the accelerator - 2-methylimidazole (0.2 m. h.) (Modifier, LLC, Tomsk, Russia).

All preforms were impregnated by VaRTM at a room temperature of $23^{\circ} \mathrm{C}$ and a pressure of -1 atm for 30 minutes. After impregnation the preforms were cured for 4 hours at $110{ }^{\circ} \mathrm{C}$.

The resulting reinforced plates were cut into samples of the required sizes for testing for short-beam bending (at quasi-static and dynamic loading speeds), tension and compression using the universal Zwick Roell Z100 testing machine (Zwick GmbH \& Co. KG, Germany). The structure was studied using a Bruker SkyScan 1172 microtomograph and a PhenomPro X scanning electron microscope.

The three-point bending test [9] under quasi-static loading was carried out on flat samples $8 \mathrm{~mm}$ in width, 44 $\mathrm{mm}$ in length and $3 \div 4.4 \mathrm{~mm}$ in thickness. The loading rate was $10 \mathrm{~mm} / \mathrm{min}$. To exclude the effect of shear stress during bending, the distance between the supports $l$ was chosen so that the ratio $l$ to the sample thickness of more than 20 was achieved.

The bending strength $\sigma_{\mathrm{s}}(\mathrm{MPa})$ was determined according to the formula:

$\sigma_{s, d, b}=\frac{3 F_{\max } l}{2 b h^{2}}$

where $F_{\max }$ is the load corresponding to the destruction of the sample, $b$ is the sample width, $h$ is the sample thickness, and $l$ is the distance between the supports.

The total fracture energy $\mathrm{A}_{\mathrm{fs}}$ was calculated according to the formula:

$A_{f s}=\frac{\int_{l_{0}}^{l_{i}} P(l) d l}{b h}$,

where the integral expression is the area under the load-deflection curve from the initial deflection $l_{0}$ to the deflection $l_{\mathrm{i}}$, b is the sample width, and $h$ is the sample thickness.

The three-point bending test [10] under of low-velocity impact conditions was carried out on flat samples $8 \mathrm{~mm}$ in width, $44 \mathrm{~mm}$ in length and $3 \div 4.4 \mathrm{~mm}$ in thickness. The movement rate of the impactor was $4 \mathrm{~m} / \mathrm{s}$ (impact energy of $13 \mathrm{~J}$ ).

The bending strength $\sigma_{\mathrm{d}}(\mathrm{MPa})$ was determined according to the formula (1).

The total fracture energy $\mathrm{A}_{\mathrm{fd}}$ was calculated according to the formula:

$A_{f d}=\left[v-\frac{1}{2 m} \int_{t_{0}}^{t_{t}} P(t) d t\right] \cdot \int_{t_{0}}^{t_{i}} P(t) d t$,

where $v$ is the velocity of the impactor at the time of contact with the sample, $m$ is the weight of the impactor, the integral expression is the area under the load-time curve from the initial moment of loading $t_{0}$ to $t_{i}$.

The four-point bending test [9] was carried out on flat samples $14 \mathrm{~mm}$ in width, $76 \mathrm{~mm}$ in length and $3 \div 4.4 \mathrm{~mm}$ in thickness. The loading rate was $10 \mathrm{~mm} / \mathrm{min}$.

The bending strength $\sigma_{\mathrm{b}}(\mathrm{MPa})$ was determined according to the formula (1).

The elasticity modulus $\mathrm{E}_{\mathrm{b}}$ was calculated according to the formula:

$E_{b}=\frac{0,21 \Delta F L^{3}}{b h^{3} \Delta \omega}$

where $\Delta \omega$ is the difference in the deflections $\omega^{`}$ and $\omega^{\prime \prime}, \Delta \mathrm{F}$ is the increment of load in the elastic section of the load corresponding to the change in the deflection $\Delta \omega$.

The torsion test [11] was carried out on flat samples $80 \mathrm{~mm}$ in width, $80 \mathrm{~mm}$ in length and $3 \div 4.4 \mathrm{~mm}$ in thickness. The loading rate was $1 \mathrm{~mm} / \mathrm{min}$.

The shear modulus of elasticity $\mathrm{G}$ was determined according to the formula:

$G=\frac{3 F l^{2}}{h^{3} \cdot \Delta l}$

where $\mathrm{F}$ is the load applied to the corner of the sample, $h$ is the sample thickness, $l$ is the distance between the supports, and $\Delta l$ is the deflection under the point of force application.

Using the loading diagram by the least squares method, the coefficient $k$ was determined in the linear equation $\mathrm{y}=\mathrm{kx}$, where $\mathrm{y}=\mathrm{F}$, and $\mathrm{k}=\Delta l$. With regard to the found coefficient $k$, the shear modulus $\mathrm{G}$ was calculated according to the formula:

$G=k \frac{3 l^{2}}{h^{3}}$

The tensile strength was calculated using the formula:

$\sigma_{P}=\frac{F_{p}}{b h}$

The compressive strength was calculated using the formula:

$\sigma_{c}=\frac{F_{p}}{b h}$

The statistical processing of the measurement results was performed for each type of research by calculating the mean value and the standard deviation. 


\section{Results and discussion}

Figure 1 shows typical photos of destroyed carbon fiber plastics during the three-point bend of a short beam. It can be seen that the destruction of the sewn samples (Figure 1a-1d) is localized in the central area. This type of cracking is typical for carbon fiber reinforced plastics that break when bent from normal stresses. However, in the central part of the samples longitudinal cracks are also observed, which are formed during destruction from shear stresses. In this case, the movement of cracks from shear stresses ends near the aramid fibers, which is explained by their greater resistance to crack growth. This type of destruction was typical for the entire range of technological parameters of the stripe. In the case of samples obtained by pressing, typical failures were observed - delaminations in the central area from shear stresses (Figure 1e).

In typical loading diagrams (Figures 2 and 3) forthree-point bending a fairly high level of peaks corresponding to secondary failure was observed.

It can be seen that for pressed materials the crack spread in spurts, as evidenced by high secondary load peaks. For stitched carbon fiber plastics the load fluctuation with the growth of deformation was significantly less. This may indicate that the crack in such materials spreads smoothly, without significant jumps. This mechanism of destruction is associated with the presence of aramid fiber in the structure of carbon fiber reinforced plastics. In this case, the aramid thread slows down the movement of cracks and their further development. It should be noted that the type of loading diagrams practically remained the same when changing the piercingstep or the density of carbon thread stitching.

For the four-point bend a mixed failure mechanism of the stitched samples was also observed. Figure 4 shows that the samples were destroyed from both normal and shear stresses, as evidenced by cracks that spread along and across the carbon fiber reinforced plastics. In this case, the samples are destroyed by normal stresses to a greater extent, while the development of cracks from shear stresses is inhibited by the stitching of aramid fibers. The density and piercingstep also have little effect on the type of destruction and are random. For the pressed carbon fiber plastics a typical type of failure was observed for such materials - a crack in the central area from normal stresses.

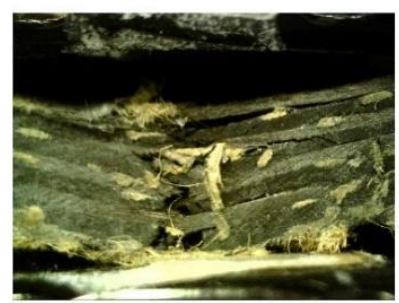

a)

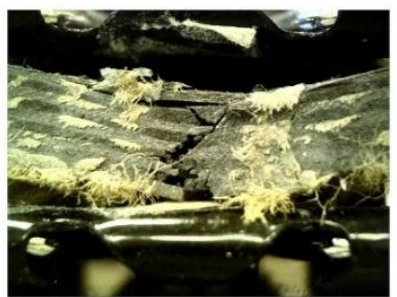

b)

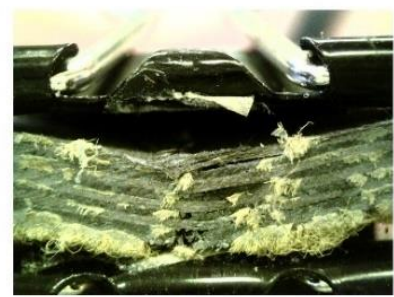

c)

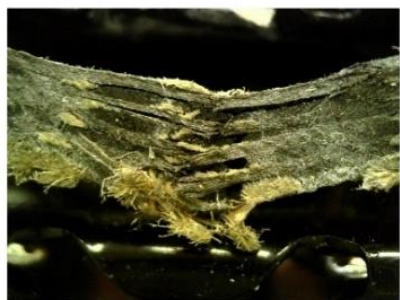

d)

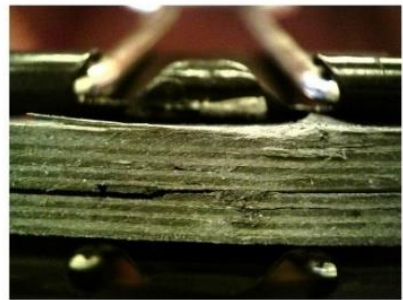

e)

Figure 1 - Typical types of destruction of the samples tested under the three-point bending, $\Delta=7 \mathrm{~mm}$. The roving laying density $\rho: a) 47 \mathrm{CU}$, b) $57 \mathrm{CU}$, c) $60 \mathrm{CU}$, d) $70 \mathrm{CU}$, e) pressed samples

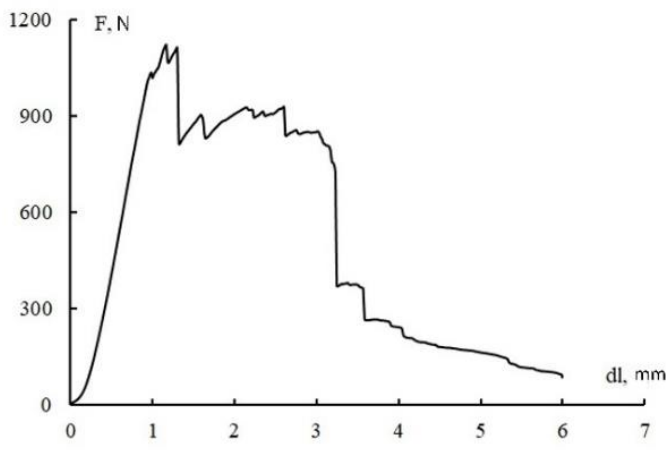

a)

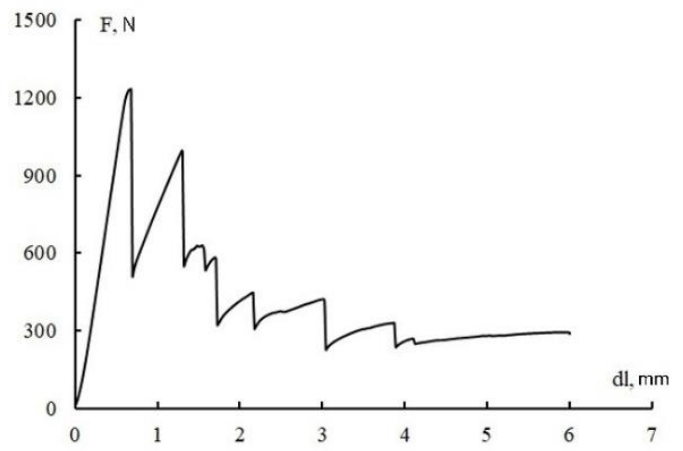

b) 
Figure 2 - Loading diagrams of stitched CFRP (a) and the pressedCFRP (b), tested for three-point bending at a quasi-static loading rate

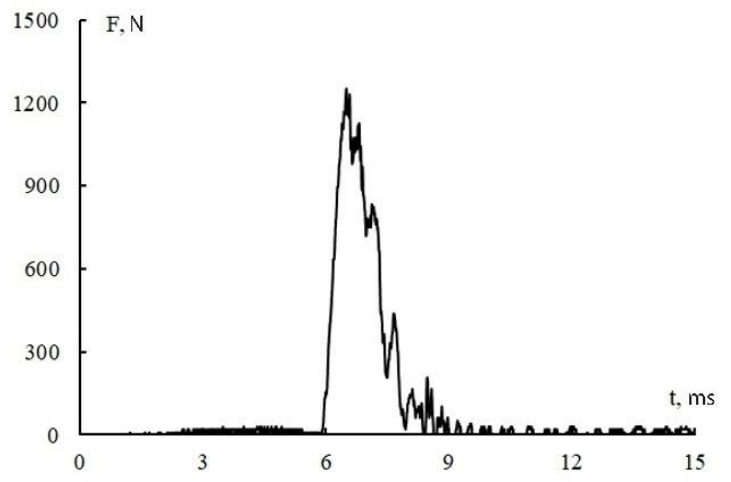

a)

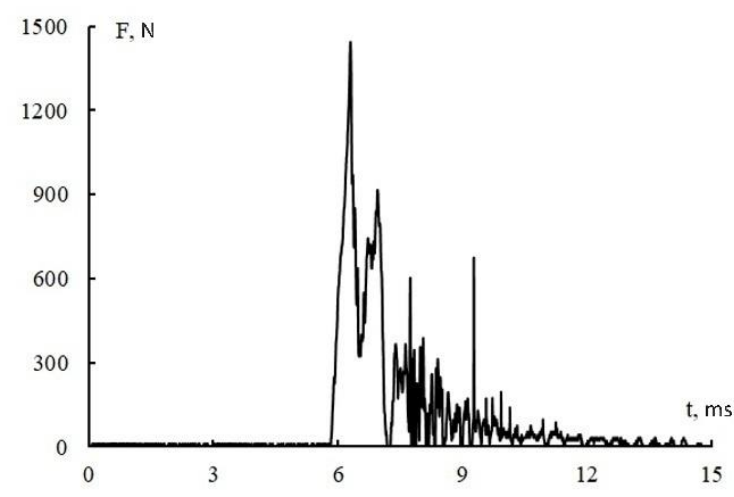

b)

Figure 3 - Loading diagrams of stitched CFRP (a) and the pressedCFRP (b), tested for three-point bending at a dynamic loading rate

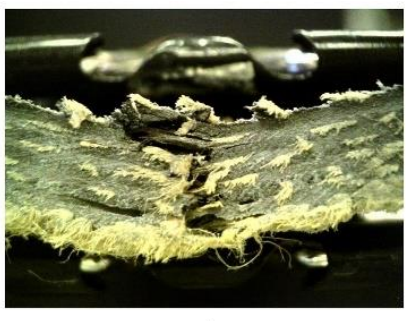

a)

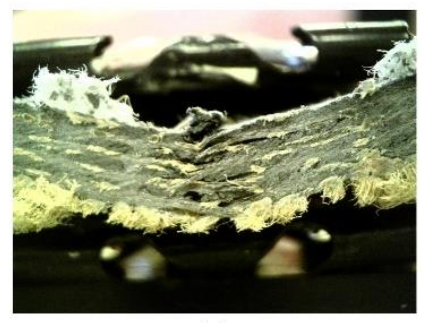

b)

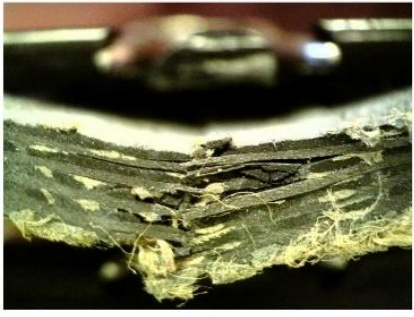

c)

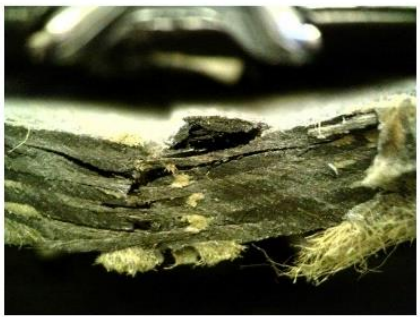

d)

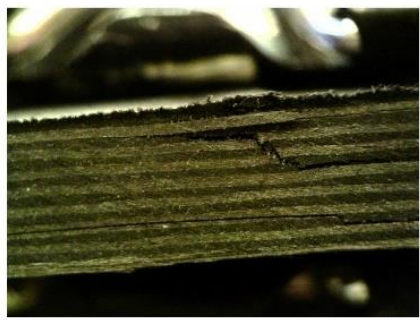

e)

Figure 4 -Typical types of destruction of the samples tested under the four-point bending, $\Delta=7 \mathrm{~mm}$. The roving laying density $\rho: a) 47 \mathrm{CU}$, b) $57 \mathrm{CU}$, c) $60 \mathrm{CU}$, d) $70 \mathrm{CU}$, e) pressed samples

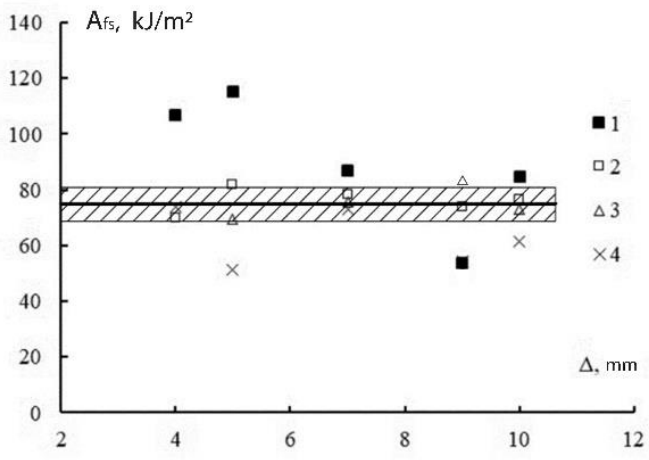

a)

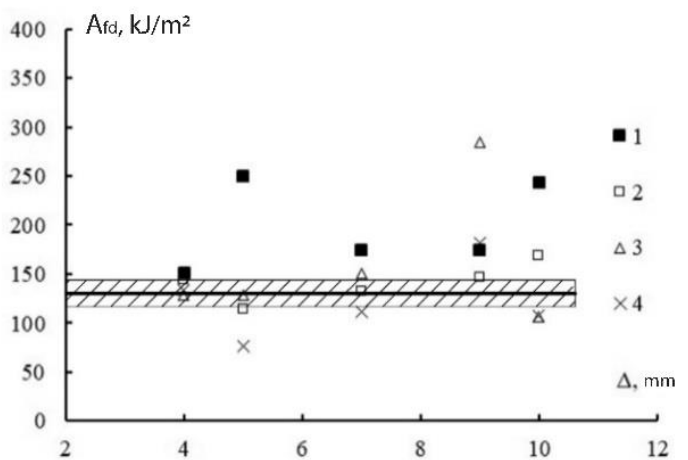

b)

Figure 5 - Dependence graphs of thefracture energy of the CFRP, tested for three-point bending at a quasi-static (a)and dynamic(b) loading rate on piercing step $\Delta$.

Roving laying densityp: 1 - 47 CU, 2 - 57 CU, 3 - 60 CU, 4 - 70 CU 


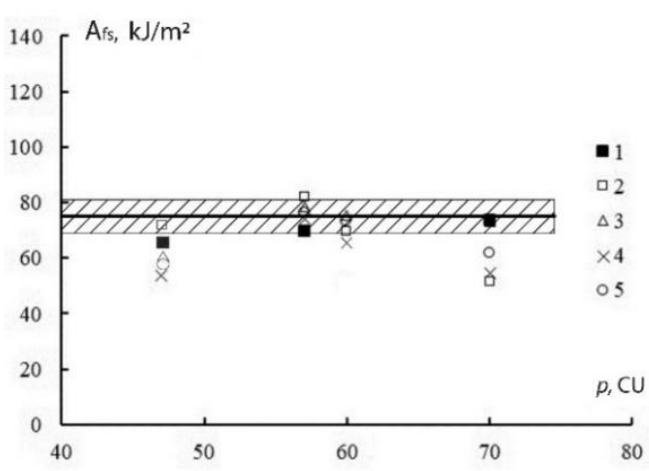

a)

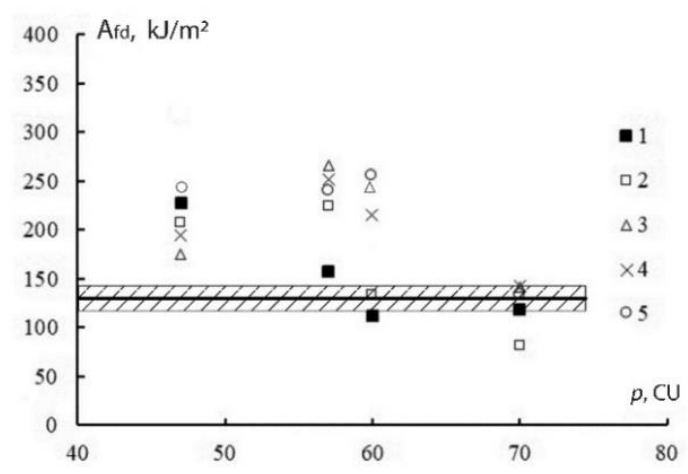

b)

Figure 6 - Dependence graphs of the fracture energy of the CFRP, tested for three-point bending at a quasistatic (a)and dynamic(b) loading rate on roving laying density $\rho$.

The piercing step $\Delta: 1-4 \mathrm{~mm}, 2-5 \mathrm{~mm}, 3-7 \mathrm{~mm}, 4-9 \mathrm{~mm}, 5-10 \mathrm{~mm}$

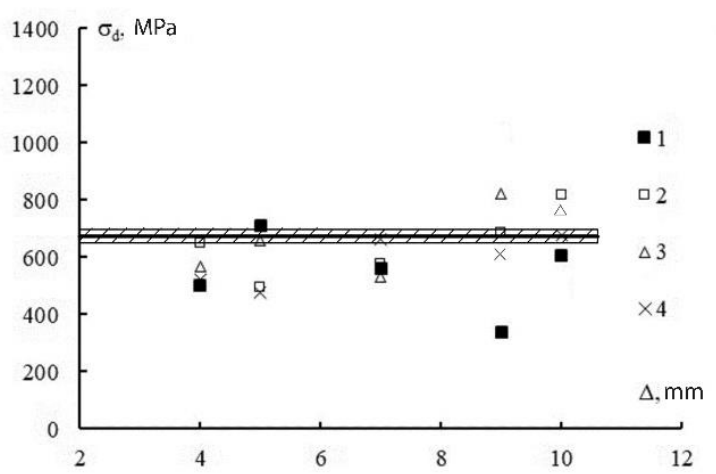

a)

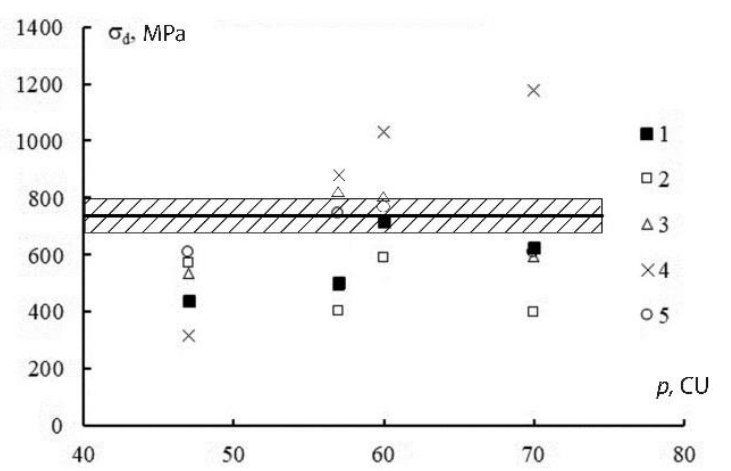

b)

Figure 7 - Dependence graphs of the strength during the three-point bending onthe piercing step $\Delta$ (a)and the roving laying density $\rho(b)$.

a) $\rho: 1-47 \mathrm{CU}, 2-57 \mathrm{CU}, 3-60 \mathrm{CU}, 4-70 \mathrm{CU}$

b) $\Delta: 1-4 \mathrm{~mm}, 2-5 \mathrm{~mm}, 3-7 \mathrm{~mm}, 4-9 \mathrm{~mm}, 5-10 \mathrm{~mm}$
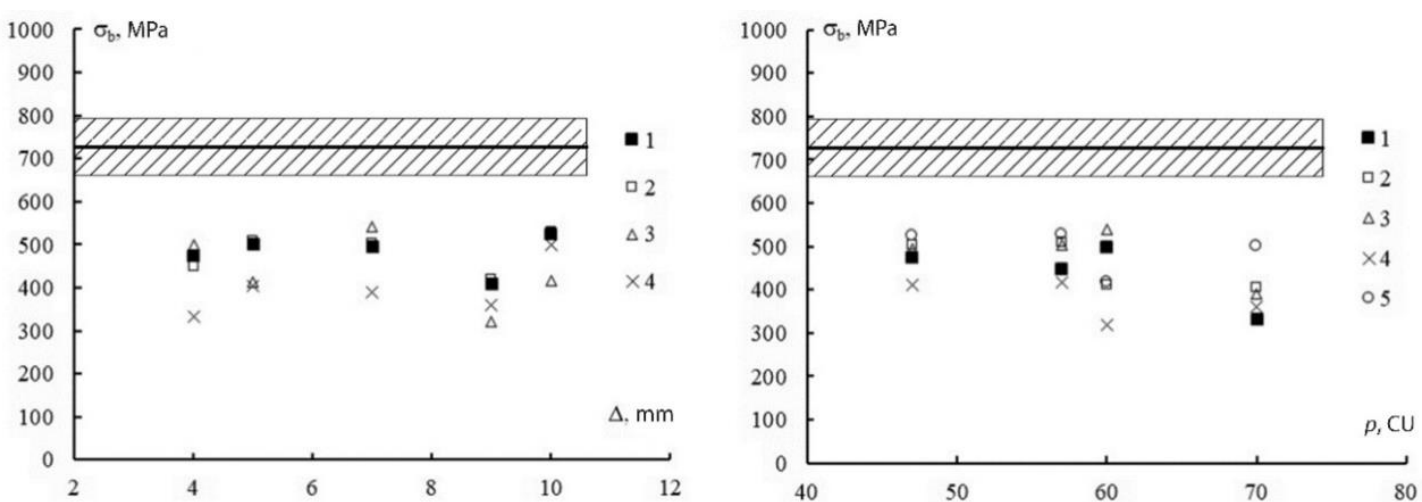

a) b)

Figure 8 - Dependence graphs of the strength during the four-point bending on the piercing step $\Delta$ (a)and the roving laying density $\rho(b)$.

a) $\rho: 1-47 \mathrm{CU}, 2-57 \mathrm{CU}, 3-60 \mathrm{CU}, 4-70 \mathrm{CU}$

b) $\Delta: 1-4 \mathrm{~mm}, 2-5 \mathrm{~mm}, 3-7 \mathrm{~mm}, 4-9 \mathrm{~mm}, 5-10 \mathrm{~mm}$ 

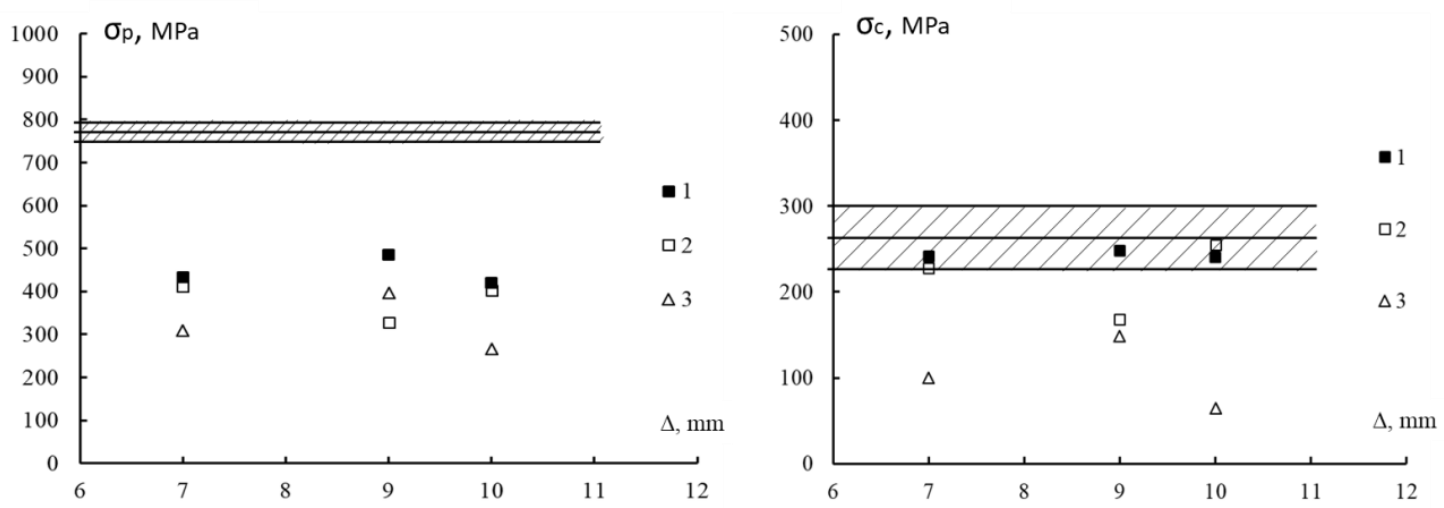

Figure 9 - Dependence graphs of the strength duringtensile (a) and compression (b) testson the piercing step $\Delta$, where $1-57 \mathrm{CU}, 2-67 \mathrm{CU}, 3-70 \mathrm{CU}$
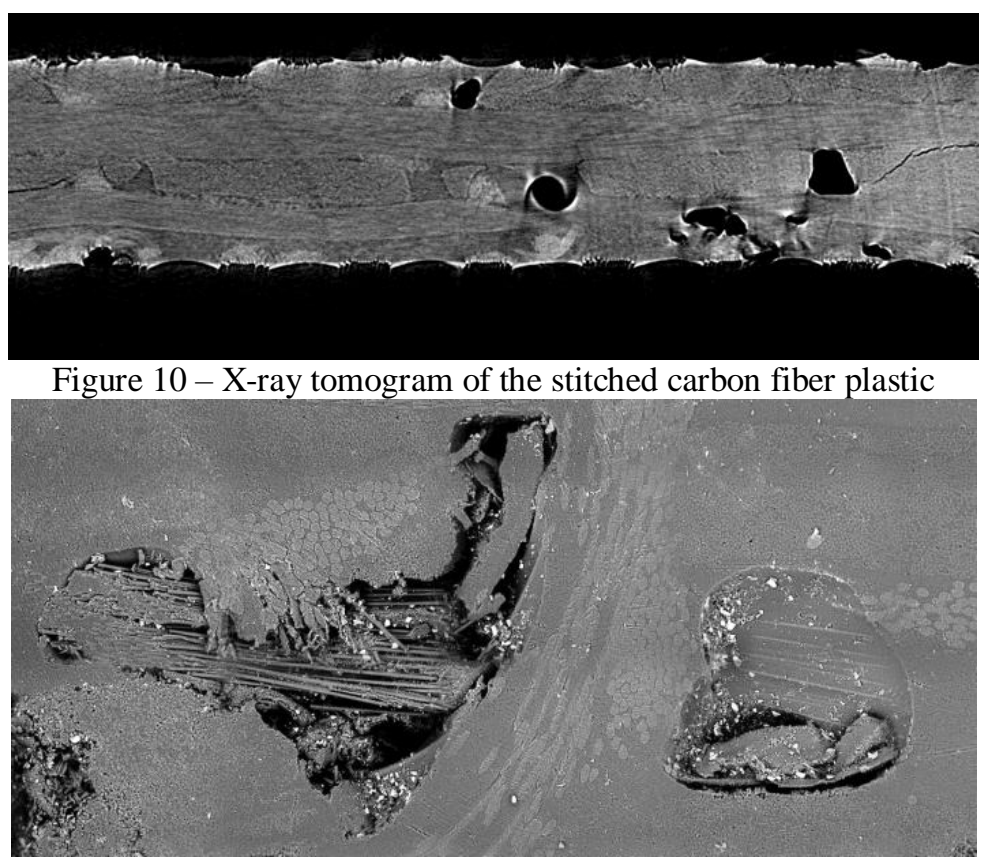

Figure 11 - Microphotography of the cross section of the stitched carbon fiber plastic

The type of loading diagrams is similar to a three-point bend: the zone of secondary destruction of stitched samples is characterized by less amplitude load jumps compared to non-abrasive carbon fiber plastics.

Figures 5-7 present the calculation results for the total fracture energy and strength of the stitched and control carbon fiber reinforced plastics under three-point benddepending on the piercing step and density and Figure 8 shows the calculation results for their strength under four-point bend. The energy level for the control sample is shown in the figures by a horizontal line, and the spread in the values of this parameter by a shaded area.

In the entire range of changes in the technological parameters of the stitching, it was not possible to obtain clear dependences of the physical and mechanical properties on the values of $\rho$ or $\Delta$. Probably, in the studied range of values of $\rho$ or $\Delta$, the strength is largely determined by the size and distribution of defects in the material. However, despite the fact that the stitching density and step as well as the direction of reinforcement do not have practically any effect on the nature of crack propagation, too frequent piercing with aramid yarns may significantly worsen the properties of the material acting as a concentrator of stress or defect created in the cross section of the sample. It is apparent that the fracture energy is consistent with the energy for the control sample and even exceeds the control values by $50 \%$ under conditions of low-velocity impact for materials with a stitching density of 57 and $60 \mathrm{CU}$ and a piercing step of 7 to $10 \mathrm{~mm}$.

The strength of both three-point and four-point bending is practically insensitive to changes in technological parameters. At the same time, the absolute strength values are almost two times lower than the strength corresponding to the non-stitched carbon fiber reinforced plastic samples. The similar situation is observed for the elasticity and shear moduli (Table 1). No clearly expressed dependences of the $\mathrm{E}$ and $\mathrm{G}$ moduli on the stitching step or density could be obtained. However, a trend toward increasing the elasticity and shear moduli 
Orlov Maksim Andreyevich, Kalinnikov Alexander Nikolayevich, Polikarpova Irina Aleksandrovna*, Bogachev Vyacheslav Vladimirovich, Kireinov Aleksey Valerievich, Solodilov Vitaly Igorevich

can be seen at a piercing step of 7 to $10 \mathrm{~mm}$ for any stitching density.

Table 1. Elasticity and shear moduli of the stitched and pressed CFRP

\begin{tabular}{|c|c|c|c|c|c|}
\hline \multirow{2}{*}{$\begin{array}{l}\rho, \\
C U\end{array}$} & \multirow{2}{*}{$\begin{array}{l}\Delta, \\
\mathrm{mm}\end{array}$} & \multicolumn{2}{|c|}{$\mathrm{E}, \mathrm{GPa}$} & \multicolumn{2}{|c|}{$\mathrm{G}, \mathrm{GPa}$} \\
\hline & & $0^{\circ}$ & $90^{\circ}$ & $+45^{\circ}$ & $-45^{\circ}$ \\
\hline 47 & 4 & 33.8 & 35.2 & 6.2 & 5.6 \\
\hline 57 & 4 & 34 & 37.9 & 5.8 & 5.9 \\
\hline 60 & 4 & 37.2 & 39.1 & 3.5 & 3.7 \\
\hline 70 & 4 & 35.5 & 34 & 7.1 & 7 \\
\hline 47 & 5 & 35.5 & 41.9 & 6.1 & 7.8 \\
\hline 57 & 5 & 35.5 & 40.5 & 6.6 & 5.2 \\
\hline 60 & 5 & 38.6 & 42.2 & 5.6 & 5.5 \\
\hline 70 & 5 & 40.2 & 38.3 & 6.6 & 5.7 \\
\hline 47 & 7 & 41.7 & 41.4 & 4.7 & 5.6 \\
\hline 57 & 7 & 41.6 & 42.3 & 7.2 & 7.4 \\
\hline 60 & 7 & 38.7 & 43.2 & 5.3 & 6.5 \\
\hline 70 & 7 & 36.5 & 38.4 & 5.8 & 6.4 \\
\hline 47 & 9 & 41.8 & 47.1 & 5.3 & 6.9 \\
\hline 57 & 9 & 43.5 & 47.2 & 5.4 & 6.7 \\
\hline 60 & 9 & 44.2 & 43 & 4.8 & 6.5 \\
\hline 70 & 9 & 36.6 & 40.6 & 5.5 & 5.1 \\
\hline 47 & 10 & 41.2 & 46.5 & 8 & 7.6 \\
\hline 57 & 10 & 46.3 & 45.7 & 11.6 & 10.2 \\
\hline 60 & 10 & 43.6 & 45.4 & 6.6 & 6.4 \\
\hline 70 & 10 & 33.3 & 35.5 & 6.5 & 6.5 \\
\hline \multicolumn{2}{|c|}{ Control (pressed) } & 79.3 & 76.9 & 10.3 & 10.5 \\
\hline
\end{tabular}

Figure 9 shows the results of measuring the tensile and compressive strength. It can be seen that the strength of the stitched carbon plastics in both cases was lower than the pressed ones, and the tensile strength was almost 2 times. At the same time, compression is less sensitive to defects.

Table 2 presents the comparative properties of pressed and stitched CFRP obtained within the optimal range of the technological parameters. It is apparent that the manufacture of products using the TFP technology allows to approach the properties of highly oriented pressed composites with high strength characteristics.

Table 2. Comparison of physical and mechanical properties of the stitched and pressed CFRP

\begin{tabular}{|l|l|l|}
\hline Parameter & $\begin{array}{l}\text { Stitched carbon fiber } \\
\text { reinforced plastic }\end{array}$ & $\begin{array}{l}\text { Pressed carbon fiber } \\
\text { reinforced plastic }\end{array}$ \\
\hline $\mathrm{A}_{\mathrm{fs}}, \mathrm{kJ} / \mathrm{m}^{2}$ & $\sim 80$ & $75 \pm 6$ \\
\hline $\mathrm{A}_{\mathrm{ds}}, \mathrm{kJ} / \mathrm{m}^{2}$ & $\sim 180$ & $126 \pm 13$ \\
\hline$\sigma_{\mathrm{s}}, \mathrm{MPa}$ & $\sim 500$ & $714 \pm 36$ \\
\hline$\sigma_{\mathrm{d}}, \mathrm{MPa}$ & $\sim 550$ & $731 \pm 61$ \\
\hline$\sigma_{\mathrm{b}}, \mathrm{MPa}$ & $\sim 550$ & $738 \pm 35$ \\
\hline $\mathrm{E}_{\mathrm{b}}, \mathrm{GPa}$ & $\sim 45$ & $79 \pm 7$ \\
\hline $\mathrm{G}, \mathrm{GPa}$ & $\sim 8$ & $10.0 \pm 0.1$ \\
\hline$\sigma_{\mathrm{p}}, \mathrm{MPa}$ & $\sim 400$ & $772 \pm 23$ \\
\hline$\sigma_{\mathrm{c}}, \mathrm{MPa}$ & $\sim 200$ & $263 \pm 37$ \\
\hline
\end{tabular}

Figures 10 and 11 show the reinforcing structures of stitched plastics obtained on microtomograph and scanning electron microscope. It can be seen that all technological modes of obtaining carbon fiber plastics are characterized by defects in the place of penetration of the material by the needle of the sewing machine. When the needle is pierced, some of the carbon nanofibers are destroyed, while the other part is bent. The formation of a loop of aramid thread contributes to the formation of pores. The pore distribution in stitchedcarbon fiber plastics requires a separate study.

Products for which high physical and mechanical properties determine the resource and reliability of their operation include gas turbine engine blades. To confirm the suitability of the developed technology, compressor blade preforms were produced for the centrifugal pump impeller (CPI). Table 3 shows the test results for the 
produced GTE compressor blades the preforms of which were obtained by manual laying of the carbon fabric on the basis of the T700 and IMS 65 carbon fibers, as well as by directional stitching of the IMS 65 carbon roving with parameters of $\rho=57 \mathrm{CU}$ and $\Delta=7 \mathrm{~mm}$.

Table 3. Comparison of compressor blade parameters

\begin{tabular}{|l|l|l|l|}
\hline Characteristics & $\begin{array}{l}\text { T700 } \\
{[0 ; 90]}\end{array}$ & $\begin{array}{l}\text { IMS 65 } \\
{[0 ;+45 ; 0 ;-45]}\end{array}$ & $\begin{array}{l}\text { IMS 65 } \\
{[0 ;+45 ; 90 ;-45]}\end{array}$ \\
\cline { 2 - 4 } & Fabric laying & Fabric laying & TFP \\
\hline Modulus of elongation $\mathrm{E}_{11}, \mathrm{GPa}$ & 88.75 & 77.86 & 59.23 \\
\hline $\begin{array}{l}\text { Shear modulus } \mathrm{G}_{12} \text { in the reinforcement } \\
\text { plane, GPa }\end{array}$ & 6.24 & 18.86 & 18.020 \\
\hline $\begin{array}{l}\text { Shear modulus } \mathrm{G}_{13} \text { in the interlaminar } \\
\text { plane during the four-point asymmetric } \\
\text { bending, GPa }\end{array}$ & 1.87 & 3.07 & 3.400 \\
\hline $\begin{array}{l}\text { Ultimate tensile strength } \sigma_{11} \text { at normal } \\
\text { temperature, MPa }\end{array}$ & 656 & 1258 & 503.62 \\
\hline $\begin{array}{l}\text { Ultimate shear strength in the } \\
\text { reinforcement plane, MPa }\end{array}$ & 83.7 & 110.76 & 142.54 \\
\hline $\begin{array}{l}\text { Ultimate interlaminar shear strength by } \\
\text { the four-point assymetric bending } \\
\text { method, MPa }\end{array}$ & 33.4 & 47.37 & 53.34 \\
\hline
\end{tabular}

The bending strength for the stitched blades was 25-30\% lower than for non-stitched carbon fiber reinforced plastics. Nevertheless, taking into account the fact that it is extremely difficult to implement an oriented fibrous structure in stitched preforms, the product maintaining the sufficient bending strength and elasticity of the samples significantly (up to $30 \%$ ) won in the shear strength.

An increase in the ultimate shear strength even by $10 \%$ in the reinforcement plane will allow to preserve to a greater extent the integrity of the finished product, preventing it from disintegrating into fragments even under operating modes close to destruction. Such a parameter is very important for GTE elements as soon as fragments formed even in a small amount often have a very high kinetic energy and are able to damage the rest engine parts.

\section{Conclusion}

The conductedstudies of the effect of the technological parameters on the physical and mechanical properties of CFRP suggest that the properties of stitched materials are consistent with the properties of pressed CFRP with a highly oriented structure the bending strength of which differs by not more than $25 \%$. Despite the fact that sewn carbon fiber plastics have strength characteristics $20-50 \%$ lower than pressed ones, it should be noted that under dynamic loading, sewn plastics have a higher energy of destruction than pressed ones. The increased energy of destruction is associated with the presence of aramid fibers in the reinforcing structure, which have a greater dissipative capacity compared to carbon fibers.

The most energy consuming structure and increased elastic-strength characteristics of stitched CFRPare realized atthe stitching step of 7-10 mm and roving laying density of 50-60 CU, which were selected as optimal for the production of GTE blades. One can hope that the crack growth in such materials and GTE blades in particularwill not be so disastrous even under impact loads in contrast to pressed carbon fiber reinforced plastics.

In addition to the achievement of a combination of physical and mechanical properties that are optimal for operation, the directional fiber stitching method possesses such advantages as the possibility to produce series of products with identical geometric, weight and strength characteristics, the absence of a human factor, and the efficient and non-waste production, which makes it promising for application in the aerospace industry.

\section{Acknowledgments}

This study was supported financially by the Ministry of Science and Higher Education of the Russian Federation in the framework of the Program for Research and Development in Priority Areas of Development of the Russian Scientific and Technological Complex for 2014-2020, subsidy agreement No.14.574.21.0160 of September 26, 2017, unique agreement identifier RFMEFI57417X0160.

\section{References}

1. P. Mattheij, K. Gliesche, D. Feltin. 3D reinforced stitched carbon/epoxy laminates made by tailored fibre placement//Composites Part A: Applied Science and Manufacturing. - 2000. - Volume 31. - issue 6. pp. 571-581. 
Orlov Maksim Andreyevich, Kalinnikov Alexander Nikolayevich, Polikarpova Irina Aleksandrovna*, Bogachev Vyacheslav Vladimirovich, Kireinov Aleksey Valerievich, Solodilov Vitaly Igorevich

2. P. J. Crothers, K. Drechsler, D. Feltin, I. Herszberg, T. Kruckenberg. Tailored fibre placement to minimize stress concentration//Composites Part A. - 1997. - Volume 28. - issue 7. - pp. 619-625.

3. A. Spickenheuer, A. Leipprand, L. Bittrich, K. Uhlig, E. Richter, G. Heinrich. Process-dependent material properties for structural simulation of composites made by tailored fibre placement//ECCM16-16th European conference on composite materials, Seville, Spain, 22-26 June 2014

4. Paul Mattheij, Konrad Gliesche, Dirk Feltin. Tailored Fiber Placement-Mechanical Properties and Applications//Journal of Reinforced Plastics and Composites. -1998. -Volume 17. - issue 9. - pp. 774786.

5. Ginger Gardiner. Tailored Fiber Placement: Besting metal in volume production//Plastic Technology. 2013. - №2

6. Carosella S. Tailored Fibre Placement - an option for automated high volume Preform Production// Symposium on Automation of Advanced Composites and its Technology, materials of conference SAMPE Europe Symposium 2012 (SEMAT). - 2012. - pp.52-58

7. H. Temment, R. Degenhardt and T. Raible. Tailored Fiber Placement Optimization Tool // the 25th Int. Congress of the Aeronautical Sciences, 2006, Hamburg, ICAS - 2006. - pp. 576-583.

8. M. A. Orlov, I. A. Polikarpova and V. I. Solodilov. Research of physical and mechanical properties of reinforced carbon fiber plastics based on tfp-preforms // IOP Conference Series: Materials Science and Engineering. - 2020. -V. 934. - p. 012066

9. ISO 14125:1998 «Fibre-reinforced plastic composites. Determination of flexural properties»

10. Solodilov V. I., Korokhin R. A., Gorbatkina Y. A., Kuperman A. M. Comparison of Fracture Energies of Epoxy-polysulfone Matrices and Unidirectional Composites Based on Them // Mechanics of Composite Materials.- 2015. - №51(2).-pp. 177-190.

11. ISO 14130:1997 «Fibre-reinforced plastic composites. Determination of apparent interlaminar shear strength by short-beam method». 